Ketahanan pukul takik untuk filler kapur makin tinggi de-

gan bertambahnya pemakaian filler, dan untuk filler kaolin penakaian makin bertambah ketahanan pukul takik makin renah. Ketahanan pukul takik tertinggi untuk filler kapur adalah , $34 \mathrm{~kg} \mathrm{~cm} / \mathrm{cm}$ pada penambahan $135 \mathrm{phr}$ dan untuk filler kaoin ketahanan pukul takik tertinggi adalah $1,99 \mathrm{~kg} \mathrm{~cm} / \mathrm{cm}$ pada enambahan 75 phr. Sedangkan untuk pemakaian filler campurin kapur dan kaolin ketahanan pukul takik naik sampai pemaaian kapur $40 \mathrm{phr}$ dan kaolin $50 \mathrm{phr}$, yaitu $2,98 \mathrm{~kg} \mathrm{~cm} / \mathrm{cm}$, kenudian akan menurun.

\title{
PENDAHULUAN
}

Filler memainkan peranan yang penting dalam industri lastik, filler didefinisikan sebagai bahan padat yang umumnya igunakan dalam jumlah besar. Kapur dan kaolin merupakan baan filler yang banyak digunakan dalam campuran plastik, keva bahan mempunyai tersebut mempunyai pengaruh yang bereda terhadap barang jadi plastik. (Du Bois. 1978).

Kapur dapat mempunyai sifat kekakuan dan kekerasan, seangkan kaolin dapat mempengaruhi kekakuan, kekerasan, ketaanan pukul dan kestabilan dimensi (Harry 1978). Sedangkan enggabungan penggunaan filler kapur dan filler kaolin dalam lastik, digunakan secara spesifik untuk memperbaiki hasil moling yaitu : mengurangi pengerutan dan penyusutan, menaikkan ekerasan dan mengurangi peresitas serta lebih padat (Oloosky 964).

Hasil pengujian acuan sepatu dari plastik yang terbuat ari resin HDPE mempunyai kekerasan 66 shore D dan ketahann pukul takik $11 \mathrm{~kg} \mathrm{~cm} / \mathrm{cm}$ (Siti Rochani 1983).

Tujuan penelitian ini untuk mendapatkan seberapa jauh engaruh penggunaan filler kapur dan filler kaolin| dan filler ampuran kapur dengan kaolin terhadap sifat kekerasan dan keahanan pukul takik kompon PVC.

Penambahan filler dalam campuran dilakukan tiga tahap enelitian komposisi.

mencampur filler kapur dalam kompon PVC.

mencampur filler kaolin dalam kompon PVC.

) mencampur dua macam filler kapur dengan filler kaolin dalam kompon PVC.

\subsection{Bahan.}

Bahan yang digunakan resin Poly Vinyl Chloride EH 1000 (PVC) plasticizer Dioktyl Phtalat (DOP) 30 phr (perhundred resin) Stabilizor Barium-Cadmiun-Zink Stearate $3,5 \mathrm{phr}$; anti oksidan asam stearat 0,5 phr dengan penambahan filler kapur dan kaolin bervariasi 75 ; $90 ; 105 ; 120 ; 135 \mathrm{phr}$ dan untuk filler campuran kapur dengan kaolin denaan variasi kapur $35 ; 40 ; 45 ; 50 ; 55$ phr dan variasi kaolin $40 ; 50 ; 60 ; 70 ; 80$ phr.

\subsection{Peralatan.}

Peralatan yang digunakan adalah : timbangan, mixer, two roll mill, Hydroulic press, cetakan dan stop watch.

2. Prosedur Penelitian.

2.1. Proses Pembuatan Kompon.

Pembuatan kompon dilakukan dalam dua tahap dengan menggunakan mixor pengaduk dan two roll mill.

Tahap I.

Bahan yang sudah ditimbang dicampur dengan alat mixer pengaduk, resin PVC dan DOP terlebih dahulu dicampur sampai merata kemudian tambahkan asam stearat, stabilizor aduk sampai merata baru kemudian ditambahkan filler dan aduk sampai campuran merata.

Tahap II.

Setelah dilakukan pencampuran tahap I, untuk penyempurnaannya dilakukan dengan two roll mill pada suhu roll $50-80^{\circ} \mathrm{C}$ dengan kecepatan roll $10 \mathrm{rpm}$, dan 8,65 rpm.

2.2. Pembuatan Slep uji.

Bahan yang sudah dicampur dibuat slep uji dengan ukuran $(150 \times 200 \times 3) \mathrm{mm}$ dengan alat Hydroulic press pada kondisi proses suhu $170^{\circ} \mathrm{C}$, tekanan $160 \mathrm{~kg}$ $\mathrm{cm} / \mathrm{cm}^{2}$ dan waktu 10 menit.

\subsection{Pengujion.}

Slep contoh uji disimpan dalam ruangan kondisi selama 
\pm 24 jam, setelah itu dipotong menurut ukuran persyaratan uji untuk masing-masing pengujian.

Pengujian dilakukan terhadap kekerasan menggunakan alat Shore Durometer dengan cara uji SII 0511 - 81 dan uji ketahanan pukul takik dengan alat Universal Impact Tester dengan cara uji SII 0673-83.

\section{HASIL PENELITIAN DAN PEMBAHASAN}

Tabel 1 Hasil Uji Kekerasan Kompon PVC dengan variasi Kapur dan Kaolin (shore D).

\begin{tabular}{l|ccccc}
\hline \multirow{3}{*}{ Filler } & \multicolumn{5}{|c}{ Konsentrasi } \\
\cline { 2 - 6 } & 75 & 90 & 105 & 120 & 135 \\
\hline Kapur & 68 & 69 & 70 & 70 & 72 \\
& 68 & 68 & 69 & 69 & 72 \\
& 68 & 69 & 69 & 70 & 70 \\
& 68 & 69 & 69 & 70 & 71 \\
& 68 & 68 & 70 & 70 & 71 \\
\hline Rata-rata & 68,0 & 68,6 & 69,4 & 69,8 & 71,2 \\
\hline Kaolin & 70 & 71 & 70 & 73 & 74 \\
& 70 & 70 & 72 & 72 & 73 \\
& 69 & 70 & 73 & 74 & 74 \\
& 69 & 72 & 73 & 73 & 74 \\
& 69 & 72 & 72 & 74 & 75 \\
\hline & 69,4 & 71,0 & 72,0 & 73,2 & 74,0 \\
\hline
\end{tabular}

Tabel 2 Analisa Sidik Ragam Uji Kompon PVC dengan variasi Kapur dan Kaolin.

\begin{tabular}{l|r|r|r|c}
\hline \hline Sumber Variasi & dk & \multicolumn{1}{|c|}{ JK } & R JK & Fhit \\
\hline Rata-rata & 1 & $249.641,78$ & $249.641,78$ & - \\
Filler (A) & 1 & 79,38 & 79,38 & $144,33 \times x$ \\
Konsentrasi B & 4 & 90,52 & 22,63 & $41,15 \times x$ \\
Interaksi AB & 4 & 5,32 & 1,33 & 2,42 \\
Error & 40 & 22,00 & 0,55 & - \\
\hline & 50 & $249.839,0$ & - & - \\
\hline
\end{tabular}

$x x$ : berbeda nyata.
Dari hasil analisa sidik ragam menunjukkan bahwa pada pemakaian konsentrasi filler yang sama menghasilkan kompon PVC yang berbeda pada derajad kebebasan $(1,40)$ yaitu sebesar 144,33 dengan $F$ 0,05.

Kekerasan kompon PVC yang menggunakan filler kaolin lebih tinggi dari kompon PVC yang menggunakan filler kapur dan kedua filler akan menaikkan kekerasan dengan naiknya jumlah pemakaian filler.

Tabel 3 Hasil Uji Pukul Takik Kompon PVC dengan Filler $\mathrm{Ca} \mathrm{CO}_{3}$ dan Kaolin $\mathrm{kg} \mathrm{cm} / \mathrm{cm}$.

\begin{tabular}{l|ccccc}
\hline \hline \multirow{3}{*}{ Macam Filler } & \multicolumn{5}{|c}{ Konsentrasi } \\
\cline { 2 - 6 } & 75 & 90 & 105 & 120 & $1 j$ \\
\hline \multirow{4}{*}{$\mathrm{Ca} \mathrm{CO}_{3}$ (Kapur) } & 3,76 & 3,56 & 4,63 & 3,78 & 4,63 \\
& 3,78 & 3,58 & 4,53 & 3,80 & 4,25 \\
& 3,15 & 3,65 & 3,82 & 4,03 & 4,28 \\
& 3,36 & 3,72 & 3,37 & 4,41 & 4,27 \\
& 4,06 & 3,97 & 3,42 & 4,44 & 4,27 \\
\hline Rata-rata & 3,62 & 3,70 & 3,93 & 4,09 & 4,34 \\
\hline \multirow{3}{*}{ Kaolin } & 2,10 & 2,67 & 1,70 & 1,42 & 1,45 \\
& 2,12 & 1,35 & 1,56 & 1,43 & 1,51 \\
& 2,05 & 1,31 & 1,26 & 1,45 & 1,48 \\
& 1,82 & 1,33 & 1,62 & 1,41 & 1,41 \\
Rata-rata & 1,84 & 2,66 & 1,56 & 1,44 & 1,31 \\
\hline
\end{tabular}

Tabel 4 Analisa Sidik Ragam hasil uji pukul takik kompon PVC dengan filler Kapur dan Kaolin.

\begin{tabular}{l|r|r|r|c}
\hline \hline Sumber Variasi & $d k$ & JK & R JK & Fhit \\
\hline Rata-rata & 1 & 390,21 & 390,21 & - \\
Filler (A) & 1 & 65,25 & 65,35 & $6,78 \times$ \\
Konsentrasi (B) & 4 & 0,131 & 0,03 & 0,00 \\
Interaksi AB & 4 & 393,13 & 98,28 & $10,19 \times x$ \\
Kekeliruan & 40 & 385,40 & 9,64 & - \\
\hline Jumlah & 50 & 463 & - & - \\
\hline
\end{tabular}

$x$ berbeda nyata.

$x x$ berbeda sangat nyata.

Vol.V.No.9 1989/1990 
Hasil analisa sidik ragam menunjukkan bahwa pukul tak kompon PVC pada pemakaian filler yang sama menghasilan pukul takik kompon PVC yang berbeda pada derajad kebeusan $(1,40)$ yaitu sebesar $6,78 \mathrm{~kg} \mathrm{~cm} / \mathrm{cm}$ dengan $F \quad 0,05$.

Ketahanan pukul takik kompon PVC yang menggunakan ller kapur lebih tinggi dari pada kompon PVC yang menggunaan filler kaolin.

1 ler kapur akan menaikkan ketahanan pukul takik dengan berambahnya jumlah pemakaian filler, sedangkan filler kaolin kan menurunkan ketahanan pukul takik dengan bertambahnya ller.

abel 5 Hasil Uji Kekerasan Kompon PVC dengan filler Campuran Kapur dan Kaolin (Shore D).

\begin{tabular}{|c|c|c|c|c|c|}
\hline \multirow{2}{*}{ aolin } & \multicolumn{5}{|c|}{ Kapur } \\
\hline & 35 & 40 & 45 & 50 & 55 \\
\hline & 73 & 73 & 75 & 74 & 76 \\
\hline & 73 & 74 & 74 & 75 & 75 \\
\hline 0 & 72 & 74 & 75 & 75 & 76 \\
\hline & 72 & 73 & 73 & 75 & 76 \\
\hline & 72 & 73 & 75 & 75 & 75 \\
\hline ata-rata & 72,4 & 73,4 & 74,4 & 74,8 & 75,6 \\
\hline & 72 & 73 & 75 & 75 & 75 \\
\hline & 73 & 74 & 74 & 75 & 76 \\
\hline 0 & 73 & 73 & 74 & 76 & 76 \\
\hline & 72 & 74 & 75 & 75 & 76 \\
\hline & 73 & 74 & 75 & 76 & 76 \\
\hline ata-rata & 72,6 & 73,6 & 74,6 & 75,2 & 75,8 \\
\hline & 74 & 75 & 75 & 77 & 76 \\
\hline & 74 & 76 & 76 & 76 & 77 \\
\hline 0 & 75 & 76 & 77 & 75 & 76 \\
\hline & 74 & 76 & 76 & 76 & 77 \\
\hline & 75 & 75 & 75 & 77 & 77 \\
\hline ata-rata & 74,4 & 75,6 & 75,8 & 76,2 & 76,6 \\
\hline
\end{tabular}

Majalah Barang Kulit, Karet dan Plastik

\begin{tabular}{l|lllll}
\hline \multirow{5}{*}{70} & 75 & 76 & 76 & 77 & 76 \\
& 75 & 74 & 76 & 77 & 78 \\
& 74 & 75 & 76 & 77 & 77 \\
& 74 & 76 & 76 & 76 & 77 \\
\hline Rata-rata & 75 & 76 & 76 & 76 & 78 \\
\hline \multirow{5}{*}{80} & 74,6 & 75,4 & 76,0 & 76,6 & 77,0 \\
\hline & 75 & 75 & 76 & 77 & 78 \\
& 75 & 76 & 77 & 78 & 77 \\
& 75 & 76 & 76 & 76 & 77 \\
\hline Rata-rata & 75 & 76 & 77 & 77 & 77 \\
\hline
\end{tabular}

Tabel 6 Analisa sidik ragam hasil uji kekerasan kompon PVC dengan filler campuran kalsium karbonat dan kaolin.

\begin{tabular}{|c|c|c|c|c|}
\hline Variasi & $\mathrm{dk}$ & JK & RJK & $F$ hit \\
\hline $\begin{array}{l}\text { Rata-rata } \\
\text { Perlakuan }\end{array}$ & 1 & $708.083,712$ & $70.883,712$ & - \\
\hline A. Kapur & 4 & 109,008 & 27,251 & $7,9 \times x)$ \\
\hline B. Kaolin & 4 & 94,768 & 23,692 & $6,91 \times x)$ \\
\hline$A B$ & 16 & 3,712 & 0,235 & 0,068 \\
\hline Kekeliruan & 100 & 342,8 & 3,428 & - \\
\hline Jumlah & 125 & 708.634 & - & - \\
\hline
\end{tabular}

Hasil analisa sidik ragam kekerasan kompon PVC hasil uji pada pemakaian tingkat konsentrasi yang bervariasi menghasilkan kekerasan kompon yang berbeda.

Penambahan konsentrasi filler kapur kedalam filler kaolin yang tetap menghasilkan kekerasan kompon yang berbeda pada derajat kebebasan (4:100) yaitu sebesar 7,95 pada $F \quad 0,05$, demikian juga penambahan filler kaolin kedalam filler kapur yang tetap akan menghasilkan kekerasan yang berbeda pada derajat kebebasan $(4: 100)$ yaitu sebesar 6,91 pada $F$ 0,05. Kekerasan kompon PVC makin naik dengan naiknya jumlah pemakaian kedua filler, kenaikan kekerasan sebanding dengan jumlah penambahan kedua campuran filler.

Vol.V.No.9 1989/1990
31 
Tabel 7 Hasil uji pukul takik kompon PVC dengan filler campuran kapur dan kaolin $(\mathrm{kg} \mathrm{cm} / \mathrm{cm})$.

\begin{tabular}{|c|c|c|c|c|c|}
\hline \multirow{2}{*}{ Kaolin } & \multicolumn{5}{|c|}{ Kapur } \\
\hline & 35 & 40 & 45 & 50 & 55 \\
\hline 40 & $\begin{array}{l}2,68 \\
2,70 \\
2,73 \\
2,68 \\
2,83\end{array}$ & $\begin{array}{l}2,75 \\
2,73 \\
2,82 \\
2,75 \\
2,05\end{array}$ & $\begin{array}{l}2,60 \\
2,60 \\
2,58 \\
2,79 \\
2,38\end{array}$ & $\begin{array}{l}2,60 \\
2,62 \\
2,64 \\
2,28 \\
2,79\end{array}$ & $\begin{array}{l}2,87 \\
2,76 \\
2,76 \\
2,78 \\
3,12\end{array}$ \\
\hline Rata-rata & 2,72 & 2,82 & 2,57 & 2,57 & 2,86 \\
\hline 50 & $\begin{array}{l}2,81 \\
2,79 \\
2,76 \\
2,83 \\
2,81\end{array}$ & $\begin{array}{l}2,96 \\
2,99 \\
2,96 \\
2,99 \\
2,99\end{array}$ & $\begin{array}{l}2,54 \\
2,51 \\
2,24 \\
2,22 \\
2,21\end{array}$ & $\begin{array}{l}2,91 \\
2,93 \\
2,93 \\
2,92 \\
2,96\end{array}$ & $\begin{array}{l}2,95 \\
2,74 \\
3,14 \\
2,95 \\
3,10\end{array}$ \\
\hline Rata-rata & 2,79 & 2,98 & 2,34 & 2,93 & 2,07 \\
\hline 60 & $\begin{array}{l}2,68 \\
2,69 \\
2,71 \\
2,71 \\
2,69\end{array}$ & $\begin{array}{l}2,71 \\
2,71 \\
2,91 \\
2,92 \\
2,94\end{array}$ & $\begin{array}{l}2,61 \\
1,93 \\
1,89 \\
2,19 \\
1,89\end{array}$ & $\begin{array}{l}2,76 \\
2,75 \\
2,75 \\
2,36 \\
2,34\end{array}$ & $\begin{array}{l}2,67 \\
2,66 \\
2,57 \\
2,56 \\
2,54\end{array}$ \\
\hline Rata-rata & 2,73 & 2,84 & 1,90 & 2,59 & 2,59 \\
\hline 70 & $\begin{array}{l}2,63 \\
2,63 \\
2,63 \\
2,65 \\
2,58\end{array}$ & $\begin{array}{l}2,41 \\
2,67 \\
2,34 \\
2,33 \\
2,33\end{array}$ & $\begin{array}{l}2,33 \\
2,37 \\
2,26 \\
2,26 \\
2,75\end{array}$ & $\begin{array}{l}2,68 \\
2,70 \\
2,73 \\
2,67 \\
2,85\end{array}$ & $\begin{array}{l}2,26 \\
2,25 \\
2,23 \\
2,57 \\
2,19\end{array}$ \\
\hline Rata-rata & 2,63 & 2,42 & 2,39 & 2,73 & 2,30 \\
\hline 80 & $\begin{array}{l}2,04 \\
2,05 \\
1,93 \\
1,67 \\
1,69\end{array}$ & $\begin{array}{l}2,11 \\
2,09 \\
2,12 \\
2,11 \\
2,08\end{array}$ & $\begin{array}{l}2,24 \\
2,26 \\
2,30 \\
2,31 \\
2,32\end{array}$ & $\begin{array}{l}2,41 \\
2,36 \\
2,44 \\
2,49 \\
2,47\end{array}$ & $\begin{array}{l}2,47 \\
2,25 \\
2,40 \\
2,47 \\
2,41\end{array}$ \\
\hline Rata-rata & 1,87 & 2,10 & 2,28 & 2,43 & 2,40 \\
\hline
\end{tabular}

Tabel 8 Analisa sidik ragam hasil uji pukul takik kompon PVC dengan filler campuran kapur dan kaolin.

\begin{tabular}{l|c|c|c|c}
\hline Variasi & $d k$ & JK & RJK & F hit \\
\hline Rata-rata & 1 & 813,985 & 813,985 & - \\
Perlakuan & 4 & 2,109 & 0,527 & $32,33 \times x)$ \\
(A) Kapur & 4 & 5,163 & 1,291 & $79,20 \times x)$ \\
(B) Kaolin & 16 & 4,019 & 0,251 & $15,399 \times x)$ \\
AB & 100 & 1,624 & 0,016 & - \\
Kekeliruan & 125 & 826,90 & - & - \\
\hline Jumlah & & & & \\
\hline
\end{tabular}

$x x=$ berbeda nyata.

Dari analisa sidik ragam hasil uji pukul takik kompon PVC menunjukkan bahwa pada pemakaian angkat konsentrasi yang ber-variasi menghasilkan pukul takik yang berbeda.

Penambahan konsentrasi filler kapur dan filler kaolin yang tetap menghasilkan pukul takik yang berbeda pada derajat kebebasan $(4,100)$ yaitu sebesar 32,33 pada $F 0,05$. Demikian juga dengan penambahan konsentrasi filler kaolin kedalam filler kapur yang tetap menghasilkan pukul takik yang berbeda pada derajat kebebasan $(4: 100)$ yaitu sebesar 79,20 pada $F$ 0,05 .

Ketahanan pukul takik kompon PVC makin naik dengan naiknya jumlah pemakaian kedua campuran filler, kenaikkan ini sebanding dengan jumlah penambahan kedua campuran filler.

\section{KESIMPULAN}

Dari penelitian ini dapat diambil kesimpulan untuk masing-masing komposisi sebagai berikut :

1. Filler Kapur dan filler Kaolin.

\subsection{Kekerasan}

- Banyaknya filler yang digunakan dalam kompon PVC akan sebanding dengan kenaikan kekerasan kompon dari 68 shore D naik 71 shore D untuk kapur, dan dari 69,4 shore D naik 74 shore D, untuk kaolin. 
- Kompon yang menggunakan filler kaolin lebih tinggi kekerasannya dibandingkan dengan kompon yang menggunakan kapur pada komposisi yang sama. 74 shore D untuk kaolin dan 71,2 shore D untuk kapur.

1.2. Ketahanan pukul takik.

- Ketahanan pukul takik kompon PVC yang menggunakan filler kaolin turun, bila jumlah pemakaian filler makin bertambah dari $1,99 \mathrm{~kg} \mathrm{~cm} / \mathrm{cm}$ turun $1,43 \mathrm{~kg}$ $\mathrm{cm} / \mathrm{cm}$.

- Ketahanan pukul takik kompon PVC yang menggunakan filler kapur naik; bila jumlah pemakaian filler makin bertambah, dari $3,62 \mathrm{~kg} \mathrm{~cm} / \mathrm{cm}$ naik $4,34 \mathrm{~kg}$ $\mathrm{cm} / \mathrm{cm}$.

2. Filler campuran kapur dan kaolin.

\subsection{Kekerasan}

- Kekerasan kompon PVC makin naik dengan makin banyaknya filler, dan kenaikannya sebanding dengan ber tambahnya jumlah penggunaan filler, dari 72,4 shore $D$ naik 77,4 shore $D$.

- Penambahan konsentrasi campuran filler kapur dan filler kaolin yang berbeda akan menghasilkan kekerasan kompon yang berbeda.

2.2. Ketahanan pukul takik.

- Ketahanan pukul takik kompon PVC akan berbeda dengan penambahan filler kapur dan filler kaolin dengan konsentrasi yang berbeda.

- Ketahanan pukul takik untuk masing-masing campuran filler menunjukkan turun naik setiap kenaikan konsentrasi campuran filler kapur dan filler kaolin.

- Ketahanan pukul takik tertinggi terletak pada konsentrasi campuran filler kapur 40 phr dan filler kaolin 50 phr sebesar $2,98 \mathrm{~kg} \mathrm{~cm} / \mathrm{cm}$.

3. Hasil uji kompon PVC yang didapat dalam penelitian ini jika dibandingkan dengan hasil uji acuan sepatu dari plastik HDPE dapat diambil kesimpulan :

- Kekerasan memenuhi syarat.

- Ketahanan pukul takik jauh lebih kecil.

Penelitian ini dibiayai oleh anggaran proyek tahun 1984/ 1985 Balai Penelitian dan Pengembangan Industri Barang Kulit, Karet dan Plastik, untuk itu kami mengucapkan banyak terima kasih atas bantuan biaya, peralatan dan fasilitas lainnya.

Juga kami ucapkan terima kasih kepada Pusat Pengendalian Mutu Petrokimia Pramutehnik Pertamina Jakasta atas fasilitas tempat pengujian sehingga penelitian ini dapat dilaksanakan.

\section{DAFTAR PUSTAKA}

1. Du Bois, J Harry and Wayne I Pribble, Plastios Mold Engineering hand book, Van Nostrand Reinhold Com pany, New York, (1978).

2. Oleesky, Samuel S and J Gelber Mohr, Hand book of Reinforoed Plastics, Van Nastrand Reinhold Company, New York (1964).

3. Kats, Hurry and John V Mileweki, Hand book of filler and Reinforoements for Plastics, Van Nastrans Reinhold Company, New York (1978).

4. Siti Rochani Naim dkk, Acuan Sepatu dari Plastik, Balai Besar Penelitian dan Pengembangan Industri Barang Kulit, Karet dan Plastik, Departemen Perindustrian, Yogyakarta, (1983). 
PENGARUH PENAMBAHAN FILLER KAPUR DAN KAOLIN TERHADAP KEKERASAN DAN PUKUL. TAKIK KOMPON PVC

Oleh : Sofyan Karani dan Arum Yuniari

\section{ABSTRACT}

The objective of this study is to detect whether there is any influence on the physical quality of the PVC compound (hardness and impact resistant). Which $\mathrm{CaCO}_{3}$, kaolin and mixture of $\mathrm{CaCO}_{3}$ and kaolin as filler is added into the batch.

The more the filler added into the batch, the higher the hardness will be. The highest figure of the test result can be presented as follow : with the addition of $135 \mathrm{phr} \mathrm{CaCO}_{3}$ as filler the hardness is 71,2 shore $D$, addition $135 \mathrm{phr}$ kaolin as filler the hardness is 74,0 shore D, while with the addition of $55 \mathrm{phr}$ $\mathrm{CaCO}_{3}$ and 80 phr kaolin, the hardness is 77,0 shore D.

The more the $\mathrm{CaCO}_{3}$ filler added into the bath, the higher the impact resistance will be, whereas the more the kaolin as filler added the lower the impact resistance will be. By the addition $135 \mathrm{phr}$ of $\mathrm{CaCO}_{3}$, the highest figure of the impact resistance is $4,34 \mathrm{~kg} \mathrm{~cm} / \mathrm{cm}$ and by the addition of $\mathrm{kaolin}$ the highest figure is $1,99 \mathrm{~kg} \mathrm{~cm} / \mathrm{cm}$, with $75 \mathrm{phr}$ kaolin.

While by the addition of the mixture of $40 \mathrm{phr} \mathrm{CaCO}_{3}$ and 50 phr kaolin as filler, the highest figure is achieved at $2,98 \mathrm{~kg}$ $\mathrm{cm} / \mathrm{cm}$, and after that it will be decreased.

\section{INTISARI}

Penelitian ini bertujuan untuk mengetahui pengaruh penambahan filler kapur, kaolin dan filler campuran kapur dengan kaolin terhadap kekerasan dan ketahanan pukul takik kompon PVC.

Kekerasan makin tinggi dengan bertambahnya pemakaian filler, kekerasan tertinggi untuk filler kapur adalah 71,2 Shore D pada penambahan $135 \mathrm{phr}$ dan untuk filler kaolin adalah 74,0 Shore D pada penambahan $135 \mathrm{phr}$, sedangkan untuk filler campuran kekerasan tertinggi adalah 77,0 Shore $D$ pada penambahan kapur $55 \mathrm{phr}$ dengan kaolin 80 phr. 